\title{
Hematolojik Malinite Olan Hastalarda Yüzeyel Fungal İnfeksiyonlar: Vaka Kontrollü Çalışma
}

\section{Superficial Fungal Infections in Patients with Hematologic Malignancies: A Case-Control Study}

Berna Ülgen Altay, Zeynep Nurhan Saraçoğlu*, Nuri Kiraz**, Ayşe Esra Koku Aksu*

Buca Seyfi Demirsoy Devlet Hastanesi, Deri ve Zührevi Hastalıklar Kliniği, İzmir, Türkiye *Osmangazi Üniversitesi Tıp Fakültesi, Deri ve Zührevi Hastalıklar Anabilim Dalı, Eskişehir, Türkiye

**Osmangazi Üniversitesi Tıp Fakültesi, Mikrobiyoloji Anabilim Dalı, Eskişehir, Türkiye

\section{Özet}

Amaç: İmmun sistemi normal olan kişilerde birçok maya, küf ve dermatofit türü mantar deride ve mukozada kommensal olarak yaşayabilmektedirler. Diyabetes mellituslu hastalar, HIV-pozitif hastalar, organ transplant hastaları, malinite olan hastalar yüzeyel fungal infeksiyonların oluşumuna yatkındırlar. Bu vaka kontrollü çalışmada hematolojik malinite olan hastalardaki yüzeyel fungal infeksiyonların prevelansını, kliniğini ve mikolojik özelliklerini göstermeyi amaçladık.

Gereç ve Yöntem: Çalışmaya 2003-2004 tarihleri arasında 80 (49 erkek, 31 kadın) hematolojik malinite olan hasta ve 50 (22 erkek, 28 kadın) polikliniğimize gelen ve rastgele seçilen sağlıklı birey kontrol grubu olarak alındı. Hastaların yaş ortalaması 52 $\pm 1,85$, kontrollerinki ise $41,56 \pm 2,04$ idi. Tüm hastalar yüzeyel fungal infeksiyon açısından muayene edildi. Parmak arasından, kasıktan ve şüpheli lezyonlardan deri kazıntı örnekleri; dil sırtından mukozal sürüntü örnekleri alındı. Tırnak örnekleri de toplandı. Tüm deri ve tırnak örneklerine direkt mikroskobik inceleme yapıldı ve fungal izolasyon için Sabaraud Dextrose Agar (SDA) kullanıldı. Maya mantarları germ tüp oluşumu ile gösterildi.

Bulgular: Hematolojik malinite olan 56 (\%70) hastada herhangi vücut bölgesi derisinde üreme olurken; kontrol grubunda 21 (\%42) hastada üreme oldu. Oral mukoza her iki grupta en sık fungal izolasyonun olduğu bölge oldu. Dermatofit olmayan küflerin de yüksek oranda ürediği gözlendi (\%26). Candida albicans kültürden en fazla izole edilen cins oldu.

Sonuç: İmmunsuprese hasta grubu olan hematolojik maliniteli hastalarda yüzeyel fungal infeksiyon gelişme oranı normal popülasyona göre yüksek çıkmıştır. Çalışmamızda Candida albicans en sık izole edilen mantar türü olmuştur. En sık oral mukoza Candida infeksiyonu gözlenmiştir. Dermatofit olmayan küflerin yüksek oranda izole edilmesi uzun süreli kullanılan geniş spektrumlu antibiyotiklere, sitotoksik kemoterapilere ve antifungallere bağlanabilir. (Türkderm 2011; 45: 73-6)

Anahtar Kelimeler: İmmunsupresyon, hematolojik malinite, yüzeyel fungal infeksiyon

\section{Summary}

Background and Design: Dermatophytes, yeasts and some moulds settle on the skin and mucosal surfaces in immunocompetent individuals as commensals. Patients with diabetes mellitus, HIV-positive patients, organ transplant recipients and the patients with malignancies are predisposed to develop superficial fungal infections. We aimed to determine the prevalence, clinical and mycological features of superficial fungal infections in patients with hematologic malignancies in this case-control study.

Material and Method: Eighty patients with hematologic malignancies (49 men, 31 women) and 50 healthy individuals ( 22 men, 28 women) randomly selected at our clinical department as controls were included to this study between 2003 and 2004 . The mean age was $52 \pm 1.85$ years in patients and $41.56 \pm 2.04$ years in controls. All patients were inspected for superficial fungal infections. Skin scrapings and mucosal swabs were obtained from the toe web, inguinal region, any suspicious lesion and oral mucosa. Nail samples were also collected. All samples were examined by direct microscopy and cultured in Sabouraud dextrose agar (SDA). The yeasts were established in germ-tube production.

Yazıssma Adresi/Address for Correspondence: Dr. Berna Ülgen Altay, Buca Seyfi Demirsoy Devlet Hastanesi, Dermatoloji Kliniği, Izmir, Türkiye

Tel.: +90232 2390306 E-posta: bernaulgen19@yahoo.com Geliş Tarihi/Received: 05.08.2010 Kabul Tarihi/Accepted: 22.09.2010

Türkderm-Deri Hastalıkları ve Frengi Arşivi Dergisi, Galenos Yayınevi tarafından basılmıştır.

Turkderm-Archives of the Turkish Dermatology and Venerology, published by Galenos Publishing. 
Results: Fifty-six (70\%) of 80 patients with hematologic malignancies had fungal colonization, whereas 21 (42\%) of 50 controls had. For both groups, oral mucosa was the predominant area that fungus was mostly isolated from. A rising number of non-dermatophyte moulds (26\%) was observed. Candida albicans was the predominant agent isolated from the culture.

Conclusion: The prevalence of superficial fungal infection was higher in patients with hematologic malignancies (being immunosuppressed) than in the normal population. Candida albicans was the predominant isolated agent that was found in our study. We observed oral mucosa candidal infection mostly. The rising number of non-dermatophyte moulds is attributed to long-term use of antibiotics, cytotoxic chemotherapies and antifungals. (Turkderm 2011; 45:73-6)

Key Words: Immunosuppression, hematologic malignancy, superficial fungal infection

\section{Giriş}

Dermatofitler, mayalar ve küfler derinin ve mukozaların fungal florasını oluştururlar. İmmun sistemi normal olan kişilerde fungal flora genellikle infeksiyonlara neden olmaz. İmmun sistem çeşitli nedenlerle baskılandığında bu mantarlar baskın hale gelip fırsatçı infeksiyonlara neden olurlar.

Diyabetes mellituslu hastalar, HIV-pozitif hastalar, organ transplant hastaları, malinite olanlar, sitotoksik tedavi alanlar, immunsupresif ilaç kullanan hastalar immun sistemi baskılanmış hastalardır ve yüzeyel fungal infeksiyon gelişme riski yüksektir $^{1-4}$. Fungal infeksiyonların tüm tipleri için en önemli risk faktörleri, yoğun sitotoksik kemoterapi uygulamaları, hematopoetik kök hücre transplantasyonu, radyoterapi, kortikosteroidler, geniş spektrumlu antibiyotik ve antifungal kullanımıdır ${ }^{5}$. Uzun süreli antifungal kullanımı funguslarda direnç gelişimine ve fırsatçı fungusların ortaya çıkmasına neden olur. Şu ana kadar literatürde yer alan çeşitli çalışmalarda farklı immunsupresif hasta gruplarında gelişen fungal flora ve bu fungusların yaptıkları yüzeyel infeksiyonlar incelenmiştir ${ }^{6-11}$.

Bu çalışmada Hematoloji Bilim Dalı'nda yatarak tedavi gören 80 hematolojik malinite olan hastanın çeşitli vücut bölgelerindeki fungal flora incelendi. Bu hastalardaki klinik bulgular ortaya kondu ve normal popülasyonu temsil eden kontrol grubu ile karşılaştırılması amaçlandı.

\section{Gereç ve Yöntem}

\section{Çalışma Grupları}

Çalışmaya 1 Ekim 2003-1 Haziran 2004 tarihleri arasında Hematoloji servisinde hematolojik malin hastalık nedeniyle yatmakta olan yaşları 18-79 arasında değişen 80 hasta (49 erkek, 31 kadın) alındı. Hastaların yaş ortalaması 52 $\pm 1,85$ idi. Kontrol grubu olarak yaşları 18-76 arasında değişen 50 birey (22'i erkek, 28'i kadın) alındı. Kontrol grubunda yaş ortalaması $41,56 \pm 2,04$ idi. Hem çalışma grubundaki hastalar hem de kontrol grubundaki bireyler yüzeyel fungal infeksiyon açısından incelendi. Kontrol grubu olarak yüzeyel fungal infeksiyon klinik belirtisi göstermeyen, başka nedenlerle (saç dökülmesi, akne, ürtiker vb....) polikliniğe başvurmuş bireyler seçildi.

Tüm hastalardan ve kontrol grubundan anamnez alındı. Yanma, kaşıntı, kızarıklık gibi şikayetlerinin olup olmadığı belirlendi. Klinik belirtiler (yanma, kaşıntı, vezikül-bül, hipopigmentasyon, hiperpigmentasyon) varsa not edildi. Çalışma grubunun tam kan sayımı yapıldı ve nötropeni açısından değerlendirildi. Deri kazıntı örnekleri parmak arasından, kasıktan ve herhangi bir şüpheli lezyondan steril bisturi ile alındı. Mukozal sürüntü örneği eküvyonlu çubukla dil sırtından, tırnak örnekleri distrofik veya normal tırnaktan kazınarak toplandı.

\section{Laboratuvar Yöntemleri}

Tüm deri ve tırnak örneklerine $\% 20$ 'lik potasyum hidroksit ile direkt mikroskobik inceleme ve fungal izolasyon için kültür yapıldı. Bu amaçla hem SDA hem de kloramfenikol ve sikloheksimid ilaveli SDA kullanılarak çift plak ekim yapıldı. Plaklar $22^{\circ} \mathrm{C}$ ve $37^{\circ} \mathrm{C}$ 'de en az 4 hafta inkübasyona bırakıldı. Mukozal sürüntü örnekleri için kanlı agar ve SDA kullanıldı ve $35^{\circ} \mathrm{C}^{\prime}$ de 10 gün inkübe edildi. Tüm plaklar haftada iki kez üreme varlığı açısından kontrol edildi. Kültürlerde üreyen maya mantarları identifikasyonu için germ-tüp testi kullanıldı. Mantarların morfolojik incelemesi için mısır unlu-Tween 80 agar kullanıldı. Dermatofitler ve diğer küf mantarlarının identifikasyonu koloni morfolojisi, mikroskobik görünüm ve biyokimyasal testlerle yapıldı.

\section{İstatistiksel Analiz}

Çalışma sonuçları değerlendirilirken student's t testi ve ki-kare testi kullanılmıştır. Çalışma grubu ve kontrol grubu yaş ortalamaları hesaplanırken student's t testi kullanılmıştır. Direkt mikroskobi ve kültür sonuçlarının, çalışma grubu ile kontrol grubu ile karşılaştırılmasında ki-kare testi kullanılmıştır.

\section{Bulgular}

Çalışma grubu hastalarında yapılan fizik muayenede 21 $(\% 26,5)$ hastada oral mukozada ve dilde beyaz plaklar tespit edildi. İnguinal bölgede $11(\% 13,75)$ hastada deskuamasyon görüldü. Ayak parmak arası muayenesinde $42(\% 52,5)$ hastada deskuamasyon görülürken, $5(\% 6,25)$ hastada 4 . ve 5 . parmak arasında maserasyon vardı. Başparmak tırnağında $38(\% 47,5)$ hastada subungual keratoz tespit edildi.

Çalışma grubundaki hastalar; lenfoproliferatif hastalıklar grubu $40(\% 50)$ hasta, myeloproliferatif hastalıklar grubu $7(\% 8,75)$ hasta, akut lösemiler $28(\% 35)$ hasta ve multipl myelom 5 $(\% 6,25)$ hasta olarak 4 gruba ayrıldı. Çalışma ve kontrol grubunun vücut bölgelerine göre kültür sonuçları Tablo 1'de gösterilmiştir. Kültür sonuçlarına göre lenfoproliferatif hasta grubu ile akut lösemi hasta grubu arasında kültürde üreme olması açısından fark saptandı $(p<0,05)$. Tüm çalışma grubu ile kontrol grubu arasında oral mukoza ve parmak arası kültürde üreme olması açısından da bir fark saptandı $(p<0,05)$. Çalışma grubunda toplam 56 (\%70) hastada herhangi vücut bölgesi derisinde üreme olurken; kontrol grubunda toplam 21 (\%42) hastada üreme oldu. Iki grup arasında anlamlı fark saptandı $(p<0,01)$.

Pozitif kültür sonuçları ile altta yatan hematolojik malin hastalık, immunsupresyon süresi ve nötropeni varlığı arasındaki ilişki değerlendirildi (Tablo 2). Lenfoproliferatif hasta grubu ile 
akut lösemi hasta grubu arasında ağız mukozası ve parmak arası örneklerindeki kültürde üreme olması açısından istatistiksel olarak anlamlı fark gözlendi $(p<0,05)$. İmmunsupresyon sürelerine göre 1-3 yıl immunsuprese hastalar ile 3-5 yıl immunsuprese olan hastalar ve kontrol grubu arasında ağız mukozası kültür üremesi açısından anlamlı bir fark saptandı $(p<0,05)$, diğer gruplarda anlamlı bir fark saptanmadı ( $p>0,05)$. Beş yıldan daha uzun süreli immunsuprese olan hasta sayısı az olduğu için $(n=2)$ istatistiksel değerlendirmeye alınmadı. Nötropenik hastalarla nötropenik olmayan hastalar arasında da kültürde üreme olması açısından belirgin bir fark yoktu ( $p>0,05)$.

Çalışma grubunda $(n=41)$ ve kontrol grubunda $(n=13)$ kandida kültürde en fazla üreyen tür oldu. Çalışma grubunda kandida albicans 25 (\%31) hastada en sık izole edilen cins olurken, kontrol grubunda 11 (\%22) hastadan izole edildi. Çalışma grubunda kültürde 23 (\%26) hastada dermatofit olmayan küfler üredi. Çalışma grubumuzdaki hastaların 25'i $(\% 31,25)$ antibiyotik $(10$ günden uzun süre), 27'si $(\% 33,75)$ antifungal, 49'u $(\% 61,25)$ kemoterapi ve 14 'ü $(\% 17,5)$ kortikosteroid tedavisi almaktaydı. Uygulanan tedavilere göre kültürde üreme olma riski Tablo 3'de gösterilmiştir. Kemoterapi, kortikosteroid ve antibiyotik tedavisi alan tüm hastalarda ağız mukozası ve inguinal bölgede fungal infeksiyon gelişme riski vardır [risk oranı (RO)>1]. Antibiyotik tedavisi alan hastalarda ayrıca parmak arası ve tırnakta da fungal infeksiyon gelişme riski hesaplanmıştır (RO>1). Antifungal kullanımı ise yüzeyel fungal infeksiyonlar açısından risk oluşturmamıştır.

\section{Tartışma}

İmmun sistemi normal olan kişilerde fungal flora genellikle infeksiyona neden olmaz. İmmunsupresif hastalarda deri ve mukozalarda yerleşen flora ve fırsatçı mantarların yaptığı yüzeyel infeksiyonların normal popülasyonla karşılaştırılması konusunda literatürde yer alan pek çok çalışma mevcuttur ${ }^{1,2.3 .6 .6 .9 .911}$. Bu çalışmamızda hematolojik malinite olan hastalarda yüzeyel

Tablo 1. Çalışma ve kontrol grubunun vücut bölgelerine göre pozitif kültür sonuçları

\begin{tabular}{|l|c|c|c|c|c|c|}
\hline Kültür Sonuçları & Oral Mukoza & İnguinal Bölge & Parmak Arası & Tırnak & Şüpheli Lezyon & Toplam \\
\hline $\begin{array}{l}\text { Lenfoproliferatif } \\
\text { Hastalıklar Grubu }(n=40)\end{array}$ & 23 & 3 & 12 & 10 & - \\
\hline $\begin{array}{l}\text { Myeloproliferatif } \\
\text { Hastalıklar Grubu }(n=7)\end{array}$ & 3 & - & 4 & 4 & 12 \\
\hline Akut Lösemiler $(n=28)$ & 8 & 7 & 5 & 6 & - \\
\hline Multipl Myelom $(n=5)$ & 3 & 2 & 1 & 1 & - \\
\hline Çalışma Grubu $(n=80)$ & 37 & 12 & 22 & 21 & 1 \\
\hline Kontrol Grubu $(n=50)$ & 12 & 3 & 6 & 8 & - & 29 \\
\hline
\end{tabular}

Tablo 2. Pozitif kültür sonuçları

\begin{tabular}{|c|c|c|c|c|c|c|c|}
\hline & & Ağız mukoza & Parmak arası & Tırnak & İnguinal bölge & Şüpheli lezyon & Toplam \\
\hline \multirow{4}{*}{$\begin{array}{l}\text { İmmunsupresyon } \\
\text { süresi }(n)\end{array}$} & 1 yıl ve daha kısa (55) & 23 & 15 & 14 & 9 & 1 & 62 \\
\hline & 1-3 yıl (17) & 10 & 5 & 5 & 2 & - & 22 \\
\hline & $3-5$ yıl (6) & 4 & 1 & 1 & - & - & 6 \\
\hline & 5 yıldan daha uzun (2) & - & 1 & 1 & 1 & - & 3 \\
\hline \multirow[t]{2}{*}{ Nötropeni (n) } & $\operatorname{Var}(24)$ & 8 & 5 & 8 & 5 & - & 26 \\
\hline & Yok (56) & 29 & 17 & 13 & 7 & 1 & 67 \\
\hline \multicolumn{2}{|l|}{ Kontrol (n) } & 12 & 6 & 8 & 3 & - & 29 \\
\hline
\end{tabular}

Tablo 3. Tedaviye göre pozitif kültür sayıları

\begin{tabular}{|c|c|c|c|c|c|c|c|c|c|}
\hline \multirow{3}{*}{ Örnek bölgesi } & \multicolumn{9}{|c|}{ Uygulanan tedaviler (n) } \\
\hline & \multicolumn{3}{|c|}{ Kemoterapi (49) } & \multicolumn{3}{|c|}{ Antibiyotik (25) } & \multicolumn{3}{|c|}{ Kortikosteroid (14) } \\
\hline & Alan & Almayan & RO & Alan & Almayan & RO & Alan & Almayan & RO \\
\hline Ağız mukozası & 23 & 13 & 1,03 & 12 & 25 & 1,05 & 7 & 30 & 1,1 \\
\hline İnguinal bölge & 9 & 3 & 1,71 & 5 & 7 & 1,57 & 3 & 9 & 1,57 \\
\hline Parmak arası & 12 & 10 & 0,75 & 4 & 18 & 2,44 & 2 & 20 & 0,47 \\
\hline Tırnak & 10 & 11 & 0,57 & 7 & 14 & 1,1 & 2 & 19 & 0,49 \\
\hline Şüpheli lezyon & - & - & 0 & 0 & 0 & 0 & 1 & 0 & 0 \\
\hline RO: Risk Oranı & & & & & & & & & \\
\hline
\end{tabular}


fungal infeksiyonları ve sıklığını normal popülasyonu temsil eden kontrol grubu ve literatürde yer alan diğer immunsuprese hasta gruplarının değerlendirildiği çalışmalardaki bulgular ile karşılaştırmayı amaçladık.

Çalışma grubunda en yüksek kültür üremesini $(\% 46,25)$ ağız mukozası örneklerinden elde ettik. Çalışma grubumuzda ağız mukozasından fungal izolasyonun kontrol grubundan yüksek olması, bu hastaların oral kandida infeksiyonlarına yatkın olması ve bunun kandida özofajiti ve invaziv kandidiazise ilerlemesi açısından önemlidir?.

Lenfoproliferatif, akut lösemi hasta gruplarında ve 1-5 yıl arası immunsuprese hastalarda izolasyonun daha sık olması, altta yatan hematolojik hastalığın ve uzamış immunsupresyon süresinin oral kandidiazis gelişiminde etkili faktörler olduğunu düşündürmektedir. Bu nedenle bu grup hastalarda ağız mukozasındaki kandida infeksiyonunun profilaksisi önem kazanmaktadır. Güleç ve ark. da renal transplant hastalarında kontrol grubuna göre oral kandida infeksiyonlarını daha sık saptamışlardır ${ }^{6}$. Parmak arası örnekleri kültürde üreme olması açısından ikinci sırada saptandı $(\% 27,5)$ ve kontrol grubuna göre daha yüksek oranda tespit edildi. Literatürde daha önce yapılan çalışmalarda parmak arası kültür üremesi kontrol grubu ile benzer sıklıkta tespit edilmiştii ${ }^{6,8}$. Tırnak ve inguinal bölgeden elde edilen kültür sonuçları ise diğer çalışmalarla uyumluydu, çalışma ve kontrol grubu arasında istatistiksel olarak anlamlı bir fark gözlenmedi ${ }^{6,89,11}$.

Çalışma grubundaki hastaların almakta oldukları medikal tedavilerin yüzeyel fungal infeksiyonların gelişmesi riski üzerine etkili olduğu gözlendi. Kemoterapi, kortikosteroid ve antibiyotik (10 günden fazla) tedavisi alan tüm hastalarda ağız mukozası ve inguinal bölgede dermatomikoz gelişme riski daha yüksektir (RO>1). Antibiyotik tedavisi alan hastalarda parmak arası ve tırnakta da fungal infeksiyon gelişme riskinin kontrol grubuyla karşılaştırıldığında arttığı gözlenmiştir (RO>1). Antifungal alan çalışma grubu hastalarıyla kontrol grubu karşılaştırıldığında ise sadece tırnak kültür üremesi açısından anlamlı bir fark saptandı $(R O>1)$. Steroid alan hastalarda ise oral mukozada, inguinal bölgede ve parmak arasında dermatomikoz gelişme riski yüksek hesaplanırken (RO>1), tırnakta ise daha düşük hesaplanmıştır $(R O<1)$. Virgili ve ark. azotiyopurin, siklosporin, steroid kullanan renal transplant hasta grubunda dermatomikoz gelişme riskinin daha yüksek olduğunu ortaya koymuştur ${ }^{8}$. Güleç ve ark. ise 102 renal transplant hastasında yaptığı çalışmada siklosporin ve azotiyopurin gibi immunsupresif ajanların yüzeyel fungal infeksiyon gelişmesi açısından bağımsız faktörler olduğunu ortaya koymuştur ${ }^{6}$. Nötropenik hastalar $(n=24)$ tüm çalışma grubunun \%30'unu oluşturmakta idi. Nötropenik hastalarla nötropenik olmayan hastaların tüm vücut bölgelerine göre kültür üremesi açısından anlamlı bir fark saptanmadı $(p>0,05)$. Bu sonuç çalışmamızda nötropeninin tek başına yüzeyel fungal infeksiyon gelişimi üzerinde etkili olmadığını göstermektedir.

Çalışmada immunsupresyon sürelerine göre vücut bölgelerinde pozitif kültür sonuçları karşılaştırıldı; 1-3 yıl arasında immunsupresif hastalar ile 3-5 yıl arasında immunsupresif hastaların kontrol grubuyla karşılaştırılmasında oral mukozada fungal kolonizasyon açısından istatistiksel olarak anlamlı fark saptandı $(p<0,05)$. Bir yıl ve daha az süreli immunsupresif hastalar, 1-3 yıl arasında immunsupresif hastalar ve 3-5 yıl arasında immunsupresif hastalar ile karşılaştırıldığında yüzeyel fungal infeksiyon gelişimi açısından anlamlı bir fark saptanmadı ( $p>0,05)$. Bu sonuç immunsupresyon sürelerinin yüzeyel fungal infeksiyon gelişmesi açısından tek başına etkili olmadığını göstermiştir. Güleç ve ark.'ı da immunsupresyon süreleri ile kültür sonuçları arasında fark olmadığını göstermişlerdir ${ }^{6}$. Romana ve ark. da diyabetes mellituslu hastalarda yaptıkları çalışmada, diyabet süresinin de dermatomikoz gelişimi üzerinde etkili olmadığını açıklamışlardır ${ }^{9}$.

Candida albicans çalışma grubunda $25(\% 31,25)$ hastada, kontrol grubunda 11 (\%22) hastada izole edilerek, en fazla üreyen tür olmuştur ${ }^{6}$. Candida tropicalis $\% 6$, candida glabrata ise $\% 5$ oranında kültürden izole edilmiştir. Dermatofit olmayan küfler de \%22 oranında üremiştir. Trichosporon asahii \%6, Trichosporon inkın \%2, Aspergillus terreus \%4, Rhodotofulla muciloginosa $\% 5$ oranında üremiştir. Dermatofitlerden ise Trichophyton mentagraphytes $\% 5$ oranında izole edilmiştir. Dermatofit olmayan bu küfler, hastaların hastanede yatış süreçlerinde maruz kaldıkları doğada, havalandırma sistemlerinde, toprakta ve inşaat malzemelerinde yaygın olarak bulunan fırsatçı funguslardır7. Dermatofit türü fungusların izolasyon sıklığı kontrol grubundan daha fazla değildi. Bu nedenle dermatofitlerin bu hasta grubu için normal popülasyona göre daha fazla risk oluşturduğunu düşünmüyoruz. Diyabetik hastalar ve renal transplant alıcıları ile yapılan çalışmalarda da benzer sonuçlar bildirilmiştir ${ }^{6,9}$.

Çalışmamızda sonuç olarak yüzeyel fungal infeksiyonlar hematolojik malinite olan hastalarda normal popülasyona göre daha sık gözlenmiştir. Altta yatan hastalık, uzamış immunsupresyon süresi, alınan sitotoksik kemoterapi, antibiyotik ve kortiko-steroid tedavileri, sonucu etkileyen faktörler olarak belirlenmiştir. En sık oral mukoza kandida infeksiyonu saptanmış ve en sık etken kandida albicans olarak izole edilmiştir. Oral mukoza kandida infeksiyonlarının kandida özofajitine zemin hazırlayabilmesi nedeniyle önemli olduğu ve bu hasta grubunda, bu tip infeksiyon açısından daha dikkatli olunması ve uygun görüldüğü takdirde profilaksi planlanması gerektiği kanaatindeyiz.

\section{Kaynaklar}

1. Ioannidou D, Maraki S, Kruger Krasagakis S et al: Cutenous alternariosis revealing acute myeloid leukaemia in an adult patient. Mycoses 2004;47:227-30.

2. Gupta AK, Ryder J, Summerbell RC: Fungal infections in immunocomprimised patients. J Eur Acad Dermatol Venereol 2003:17:1-2.

3. Samaranayake LP, Fidel PL, Naglik JR et al: Fungal infections associated with HIV infection. Oral Dis 2002;8:151-60.

4. Hasan MA, Fitzgerald SM, Saoudian M, Krishnaswamy G: Dermatology for the practicing allergist: Tinea pedis and its complications. Clin Mol Allergy 2004;2-5.

5. Pagano L, Caira M, Candoni A et al: The epidemiology of fungal infections in patients with hematologic malignancies: the SEIFEM2004 study. Haematologica 2006;91:1068-75.

6. Güleç T, Demirbilek M, Seçkin D et al: Superficial fungal infections in 102 renal transplant recipients: A case-control study. J Am Acad Dermatol 2003:49:187-92

7. Mays SR, Bogle MA, Bodey GP: Cutaneous fungal infections in the oncology patient: recognition and management. Am J Clin Dermatol 2006;7:31-43.

8. Virgili A, Zampino MR, La Malfa V, Strumia R, Bedani PL: Prevalence of superficial dermatomycoses in 73 renal transplant recipients. Dermatology 1999;199:31-4.

9. Romano C, Massai L, Asta F, Signorini AM: Prevalence of dermatophytic skin and nail infections in diabetic patients. Mycoses 2001;44:83-6.

10. Gupta AK, Ryder J, Summerbell RC: Fungal infections in immunocompromised patients. J Eur Acad Dermatol Venereol. 2003;17:1-2.

11. Gupta AK, Taborda $P$, Taborda V et al: Epidemiology and prevalance of onychomycosis in HIV-pozitive individuals. Int J Dermatol 2000;39:746-53. 